\title{
A BNCC E O ENSINO DE CIÊNCIAS: OPORTUNIDADES E LIMITAÇÕES
}

\author{
BNCC AND SCIENCE EDUCATION: OPPORTUNITIES AND LIMITATIONS
}

BNCC Y LA EDUCACIÓN CIENTÍFICA: OPORTUNIDADES Y LIMITACIONES

\author{
Luan Mesquita Guerra* (D) 8 \\ André Ricardo Ghidini** (D) \\ José Victor Acioli da Rosa ${ }^{* * *}$ (D) 9
}

\section{RESUMO}

A empregabilidade das TIC's no momento delicado pelo qual estamos passando se mostrou essencial para todos os setores sociais, em ênfase ao setor educacional. Dessa forma, aqui, buscou-se discutir acerca das oportunidades e limitações da utilização das TIC's na área educacional, sobretudo, no ensino de ciências, sob o enfoque da BNCC (2018), e de outros documentos oficiais da educação básica nacional, fazendo-se presente também neste estudo, ideias de autores citados ao longo do texto, acerca das TIC's. Para isso, realizou-se uma pesquisa qualitativa, de caráter exploratório, tendo como forma de coleta de dados, a pesquisa bibliográfica e documental, acerca da usabilidade das TIC's em âmbito educacional e no Ensino de Ciências. Os resultados apontaram, mediante confrontação dos trabalhos aqui tabulados, com a quinta competência geral da BNCC (2018), que as TIC's, sim, podem substancialmente alavancar o processo de ensino e aprendizagem dos alunos, no entanto, a inserção destas tecnologias ainda apresenta certas limitações, as quais deve-se intervir.

Palavras-chave: Tecnologias; ensino de ciências; ensino-aprendizagem; TIC's.

\begin{abstract}
The employability of ICT at the delicate moment we are going through has proved essential for all social sectors, in emphasis on the educational sector. Thus, here, we sought to discuss about the opportunities and limitations of the use of ICT in the educational area, especially in science teaching, under the focus of BNCC (2018), and other official documents of national basic education, also present in this study, ideas of authors cited throughout the text, about ICT's. For this, a qualitative research was carried out, of exploratory character, having as a form of data collection, the bibliographic and documentary research, about the usability of ICT's in educational and Science Teaching. The results indicated, through confrontation of the work tabulated here, with the fifth general competence of the BNCC (2018), that ICT's, yes, can substantially leverage the teaching and learning process of students, however, the insertion of these tecnologies it still has certain limitations, which must be intervened.
\end{abstract}

\footnotetext{
* Licenciando em Ciências Biológicas pela Universidade Federal do Acre (UFAC) - Campus Sede. Estudante de Licenciatura em Universidade Federal do Acre (UFAC), Rio Branco, Acre, Brasil. Travessa Cajueiro, n. 44, casa, montanhês, Rio Branco, Acre, Brasil, CEP: 69921-530. E-mail: mezquita.luan@gmail.com.

*** Doutor em Ciências Biológicas (Biologia de Água Doce e Pesca Interior) pelo Instituto Nacional de Pesquisas da Amazônia (INPA). Professor do Magistério Superior na Universidade Federal do Acre (UFAC) - Campus Sede, Campus Universitário/CCBN, BR-364, Km 04, S/N, Distrito Industrial, Rio Branco, Acre, Brasil, CEP: 69920-900. E-mail: andre.ghidini@ufac.br.

**** Mestrando em Ensino de Ciências e Matemática pela Universidade Federal do Acre (UFAC) - Campus Sede. Professor de Química pela Secretaria de Educação do Estado do Acre, (SEE/AC), Rio Branco, Acre, Brasil. Rua Veterano T Pinto, n. 439. Bairro: Conjunto Manoel Julião, Rio Branco, Acre, Brasil. CEP: 69918-412. E-mail: victoracioly.va@gmail.com.
} 
Keywords: Technologies; science teaching; teaching-learning; ICT's.

\section{RESUMEN}

La empleabilidad de las TIC en el delicado momento por el que estamos atravesando ha demostrado ser esencial para todos los sectores sociales, haciendo hincapié en el sector educativo. Así, aquí, tratamos de debatir sobre las oportunidades y limitaciones del uso de las TIC en el ámbito educativo, especialmente en la enseñanza de la ciencia, bajo el enfoque del BNCC (2018), y otros documentos oficiales de la educación básica nacional, también presentes en este estudio, ideas de autores citados a lo largo del texto, sobre las TIC. Para ello, se llevó a cabo una investigación cualitativa, de carácter exploratorio, que tiene como forma de recopilación de datos, la investigación bibliográfica y documental, sobre la usabilidad de las TIC en la enseñanza educativa y científica. Los resultados indicaron, a través de la confrontación del trabajo tabulado aquí, con la quinta competencia general del BNCC (2018), que las TIC, sí, pueden aprovechar sustancialmente el proceso de enseñanza y aprendizaje de los estudiantes, sin embargo, la inserción de estos tecnologías, todavía tiene ciertas limitaciones, que deben ser intervenidas.

Palabras clave: Tecnologías; enseñanza de ciencias; enseñanza-aprendizaje; TIC.

\section{INTRODUÇÃO}

O uso de tecnologia está cada vez mais presente no cotidiano escolar, a atual geração de alunos necessita de respostas cada vez mais rápidas e sólidas, e a escola, sendo uma instituição formadora, precisou redefinir-se e adaptar-se a essa nova geração e, sobretudo, ao momento de pandemia do novo coronavírus, iniciada em 2019, responsável por causar a doença covid-19.

Com o avanço da pandemia e atendendo às recomendações da Organização Mundial da Saúde (OMS) de manter o isolamento social, as aulas presenciais nas escolas e nas instituições de ensino superior da rede pública e privada de todo o país foram paralisadas. A partir daí, um novo modelo de ensino foi adotado, interfaces digitais passaram a ser utilizadas para contornar este momento atípico e manter a continuidade das atividades de classe.

Com esse inesperado método de ensino, coube às escolas e aos professores se adaptarem à digitalização e fazerem uso das interfaces digitais de ensino, para que, dessa maneira, pudessem dar continuidade às suas atividades escolares. Nascimento (2016) considera necessário estar atualizado com as tecnologias, para poder acompanhar o mundo e suas adversidades, o qual está cada vez mais competitivo e globalizado, exigindo profissionais mais preparados e aptos a lidar com a complexidade e diversidade das informações.

Nesse contexto, o uso das Tecnologias de Informação e Comunicação (TIC's) mostrou-se essencial para manter a continuidade das atividades de classe e profissionais em 
todos os setores da sociedade. Isso referendou, portanto, a ideia de que a tecnologia pode ser um mecanismo capaz de ampliar a eficiência das atividades humanas em todos os segmentos sociais, inclusive no segmento educacional.

Assim, o presente trabalho tem como objetivo discutir acerca das oportunidades e limitações da utilização das TIC's na área educacional, sobretudo, no Ensino de Ciências, sob o enfoque de autores e documentos oficiais.

\section{TIC's NO PRCESSO DE ENSINO-APRENDIZAGEM}

Sob a perspectiva de Miranda (2007), o termo Tecnologias da Informação e Comunicação (TIC's) refere-se à junção da tecnologia computacional com a tecnologia das telecomunicações (celulares, televisores, entre tantos outros), tendo, na internet, sua mais forte expressão.

Sob o olhar de Soares e Colares (2020), a tecnologia está a serviço da educação, e a internet, no momento que estamos vivenciando, acabou se tornando a sala de aula, o que, consequentemente, promoveu duras mudanças na forma de ensinar. $\mathrm{O}$ professor, antes frente aos alunos, em uma sala de aula física, agora, passa a recebê-los em casa, através das interfaces digitais de ensino, em uma sala de aula on-line. As interfaces digitais presentes nesse novo processo de ensino são as mais variadas possíveis, mas podem-se destacar as de mais aplicabilidade: Google Meet ${ }^{\circledR}$, Ambiente Virtual de Aprendizagem (AVA), Google Classroom $^{\circledR}$, YouTube $^{\circledR}$, e-mail $^{\circledR}$, WhatsApp $^{\circledR}$.

Inegavelmente, as tecnologias ganharam espaço em todos os setores da sociedade e foi na esfera educativa que elas obtiveram maior destaque, pois é devido à sua eficiência no processo educacional que elas passaram a ser inseridas em sala de aula como recurso didático. Os estudantes, nesse contexto, sob as considerações de Giraffa (2014), são conhecidos como "nativos"da linguagem digital, dos computadores, videogames e Internet. Portanto, são hábeis em lidar com as novas tecnologias que estão surgindo e ganhando cada vez mais espaço na rotina das pessoas.

Giassi e Ramos (2016) afirmam que o processo evolutivo ocorrido com o advento das TIC's no ensino, ao longo da história, possibilita equipar uma escola com o que há de ponta nesse sentido. Entretanto, para as autoras, as primeiras tecnologias presentes nas escolas, as quais permanecem até os dias de hoje, são o livro e o quadro de giz, que continuam dando suporte aos professores no desenvolvimento de suas práticas. 
Martinho e Pombo (2009) apontam que a inserção das TIC's no processo de ensinoaprendizagem é eficaz, pois, para as autoras, são ferramentas que podem contribuir para valorizar as práticas pedagógicas, já que possibilitam o acesso à informação com maior flexibilidade e também diversidade de suporte no seu tratamento e apresentação.

Do mesmo modo, Soffner (2013, p. 155) afirma que:

Deste ponto de vista tais tecnologias de apoio ao desenvolvimento cognitivo poderão ser consideradas tecnologias da aprendizagem. Esta aprendizagem leva ao desenvolvimento de competências para a vida, que pode ser considerada uma contínua interação entre o indivíduo e seu meio.

Com a inclusão das TIC's no processo de ensino, torna-se necessário que os docentes estejam preparados para lidar com essas tecnologias. Assim, Lima e Moita (2011) apontam que se faz necessário que o professor conheça as novas tecnologias, permitindo-se melhorar a sua prática. Segundo as autoras, o papel do professor não é simplesmente o de transmitir informações, mas de apresentá-las de forma inovadora e estimulante, de modo que o aluno se torna o sujeito da aprendizagem e não mais o objeto (LIMA; MOITA, 2011).

Isso, consequentemente, possibilita ao professor inovar e se adptar, sobretudo, ao novo modelo de ensino exigido devido à pandemia, trazendo para a sala de aula novos recursos, metodologias e estratégias de ensino. Giassi e Ramos (2016) consideram que o emprego de tecnologia no dia a dia das escolas pode representar a oportunidade de mudança do foco da aula centrada no professor para uma aula centrada no aluno, que passa a assumir o processo de seu aprendizado.

Sob a ótica de Barroqueiro, Amaral e Oliveira (2016, p. 50), "O educador para atingir os seus objetivos necessita de uma ferramenta de complementação e aperfeiçoamento na sala de aula, que são as TIC's". Ainda conforme os autores, a nova realidade exige que os educadores tenham novas competências, habilidades e atitudes.

Nesse processo, Ponte (2002) considera importante levar em conta as dificuldades inerentes à utilização de TIC's na educação, sendo relevante considerar tanto questões estruturais e materiais da escola, de formação de professores, até a problemática de ter uma visão global acerca do uso das TIC's e seus impactos na sociedade.

Partindo dessas considerações, Assis, Czelusniak, e Roehrig (2011) destacam que, embora o uso das tecnologias esteja presente em vários segmentos da sociedade e esteja ganhando espaço no meio educacional, ainda é pequena a sua projeção na educação, diante do potencial que os meios tecnológicos podem oferecer enquanto recursos pedagógicos. 
A pandemia da covid-19 acelerou o processo de inclusão das TIC's no ensino e novas estratégias de aprendizagem foram repensadas (SANTOS, 2021). As TIC's se tornaram ainda mais indispensáveis neste momento, no qual as aulas passaram a contar, quase que exclusivamente, com as tecnologias, o que modificou a forma de pensar das pessoas acerca dessas ferramentas, criou o "novo normal" e a "nova rotina", o "trabalhar e estudar em casa", resultantes do isolamento social (principal profilaxia à covid-19). Enfim, exigiu domínio sobre essas tecnologias, assim como adaptação a elas, tornando necessário e urgente inserir esse utilitário na rotina profissional e escolar.

\section{O QUE A BNCC NOS DIZ SOBRE AS TIC's E O ENSINO DE CIÊNCIAS?}

Antes de se falar abertamente sobre a posição da Base Nacional Comum Curricular (BNCC), relacionada ao uso de tecnologia no ensino, deve-se fazer um retrospecto e dissertar sobre a abordagem que outros documentos oficiais fazem acerca da presença da tecnologia no campo educacional. Esses documentos auxiliam na compreensão sobre o que a educação tem como objetivos e princípios, bem como sobre o que deve ser ensinado nas escolas do Brasil (ARRUDA, 2018).

Pode-se citar, como primeiro exemplo, a terceira versão da Lei de Diretrizes e Bases da Educação Nacional (LDBEN), datada do ano de 1996. Seus Arts. 32, 36 e 39, respectivamente, referem-se superficialmente à utilização das TIC's:

\footnotetext{
Art. 32 .

O ensino fundamental obrigatório, com duração de 9 (nove) anos, gratuito na escola pública, iniciando-se aos 6 (seis) anos de idade, terá por objetivo a formação básica do cidadão, mediante:

II - a compreensão do ambiente natural e social, do sistema político, da tecnologia, das artes e dos valores em que se fundamenta a sociedade (BRASIL, 1996, Art. 32). Art. 36.

$\S$ 11. Para efeito de cumprimento das exigências curriculares do ensino médio, os sistemas de ensino poderão reconhecer competências e firmar convênios com instituições de educação a distância com notório reconhecimento, mediante as seguintes formas de comprovação:

VI - cursos realizados por meio de educação a distância ou educação presencial mediada por tecnologias (BRASIL, 1996, Art. 36).

Art. 39. A educação profissional e tecnológica, no cumprimento dos objetivos da educação nacional, integra-se aos diferentes níveis e modalidades de educação e às dimensões do trabalho, da ciência e da tecnologia (BRASIL, 1996, Art. 39).
}

Diante do exposto, é perceptível que as TIC's não são exploradas de forma eficiente pela LDBEN, tornando-se necessário trazer, para este trabalho, as considerações dos 
Parâmetros Curriculares Nacionais (PCN's), datados do ano de 1998, acerca do uso de tecnologias. O documento defende que "A tecnologia deve servir para enriquecer o ambiente educacional, propiciando a construção de conhecimentos por meio de uma atuação ativa, crítica e criativa por parte de alunos e professores" (BRASIL, 1998, p. 140).

Dessa forma, para fins de aprofundamento nesta temática, é interessante dar ênfase às Diretrizes Curriculares Nacionais da Educação Básica (DCNEB), do ano de 2013, especialmente aos Arts. 13, 14 e 39, os quais, respectivamente, discorrem sobre o uso das tecnologias na educação:

Art. 13 .

VII - estímulo à criação de métodos didático-pedagógicos utilizando-se recursos tecnológicos de informação e comunicação, a serem inseridos no cotidiano escolar, a fim de superar a distância entre estudantes que aprendem a receber informação com rapidez utilizando a linguagem digital e professores que dela ainda não se apropriaram (BRASIL, 2013, Art. 13).

Art. 14.

$\S 3^{\circ}$ A base nacional comum e a parte diversificada não podem se constituir em dois blocos distintos, com disciplinas específicas para cada uma dessas partes, mas devem ser organicamente planejadas e geridas de tal modo que as tecnologias de informação e comunicação perpassem transversalmente a proposta curricular, desde a Educação Infantil até o Ensino Médio, imprimindo direção aos projetos políticopedagógicos (BRASIL, 2013, Art. 14).

Art. 39. A modalidade Educação a Distância caracteriza-se pela mediação didaticopedagógica nos processos de ensino e aprendizagem que ocorre com a utilização de meios e tecnologias de informação e comunicação, com estudantes e professores desenvolvendo atividades educativas em lugares ou tempos diversos (BRASIL, 2013, Art. 39).

Por conseguinte, a relação do Ensino de Ciências (anos finais) com a tecnologia está pautada, de forma mais ampla, na terceira versão da BNCC, do ano de 2018. O documento aponta que o Ensino de Ciências nos anos finais do Ensino Fundamental é caracterizado pela exploração das vivências, saberes, interesses e curiosidades dos alunos sobre o mundo natural e material (BRASIL, 2018), o que significa lançar mão do conhecimento científico e tecnológico, tornando possível, aos alunos, compreender os fenômenos e conhecer o mundo, o ambiente e a dinâmica da natureza.

Nesse sentido, o Ensino de Ciências apresenta-se de forma articulada com a tecnologia, demonstrando ampla relevância e eficácia quando o contexto das TIC's é inserido no ensino. Sob o olhar de Bertusso et al. (2020), para o Ensino de Ciências existem inúmeros recursos inovadores que podem contribuir no processo de aprendizagem. No que tange a esses recursos, Dourado et al. (2014) apontam que as TIC's se tornaram um elo entre docentes e alunos, pelo qual são desenvolvidas novas estratégias de ensino, gerando interação entre o 
aluno, o professor e o cenário atual.

Atrelado a esse processo tecnológico, é interessante dar destaque ao movimento CTS (Ciência, Tecnologia e Sociedade), no qual ciência, tecnologia e sociedade encontram-se indissociáveis. Essa integração entre ciência, tecnologia e sociedade no Ensino de Ciências, para Rubba e Wiesenmayer (1988), representa uma tentativa de formar cidadãos científica e tecnologicamente alfabetizados, capazes de tomar decisões informadas e desenvolver ações responsáveis.

Corroborando com os autores supracitados, Martins (2002) destaca que o movimento CTS para o Ensino das Ciências revela a importância do ensinar a resolver problemas, a confrontar pontos de vista, a analisar criticamente argumentos, a discutir os limites de validade de conclusões alcançadas, a saber formular novas questões.

Destacando Rubba e Wiesenmayer (1988), no que se refere ao termo “[...]tecnologicamente alfabetizados [...]", a BNCC (2018) apresenta a questão do letramento científico, o qual diz respeito à compreensão dos conceitos científicos, à habilidade de aplicar tais conceitos e de pensar sob uma ótica científica.

Sob esse enfoque, a BNCC destaca que:

[...] a área de Ciências da Natureza tem um compromisso com o desenvolvimento do letramento científico, que envolve a capacidade de compreender e interpretar o mundo (natural, social e tecnológico), mas também de transformá-lo com base nos aportes teóricos e processuais das ciências (BRASIL, 2018, p. 321).

Santana et al. (2016) afirmam que o desenvolvimento da Ciência trouxe novas tecnologias e, como resultado, um conhecimento científico diferenciado e emancipado do senso comum. Isso permite estabelecer uma relação entre as TIC's e o Ensino de Ciências, relação essa que precisa estar atrelada à capacidade de os educadores inserirem em suas práticas o conhecimento sobre os recursos tecnológicos disponíveis. Assim, possibilitando potencializar a produção de saberes, os quais são construídos de forma coletiva e colaborativa, utilizando as redes sociodigitais (LUCENA, 2016).

Estudos vêm sendo publicados sobre a temática do presente trabalho, e isso deve-se à importância que as ferramentas tecnológicas desempenham no contexto educacional. O uso das TIC's em classe escolar torna possível inovar a maneira de ensinar, sobretudo, diante do cenário atual, que tão repentinamente foi de encontro às antigas práticas pedagógicas, exigindo uma rápida adequação às tecnologias, bem como demonstrando ser indispensável o 
emprego dessas tecnologias no processo de ensino, não somente na disciplina de Ciências, mas também nas demais.

O próximo termo abordado pela BNCC (2018) referente à tecnologia é a "Cultura Digital", a qual, segundo o documento, tem promovido mudanças sociais significativas nas sociedades contemporâneas, sendo decorrente do avanço e da multiplicação das tecnologias de informação e comunicação. A tecnologia, em âmbito educacional, é contemplada pela BNCC (2018) em sua quinta competência geral, a qual aponta:

Compreender, utilizar e criar tecnologias digitais de informação e comunicação de forma crítica, significativa, reflexiva e ética nas diversas práticas sociais (incluindo as escolares) para se comunicar, acessar e disseminar informações, produzir conhecimentos, resolver problemas e exercer protagonismo e autoria na vida pessoal e coletiva (BRASIL, 2018, p. 9).

A inserção dessas tecnologias na educação, sob o olhar de Mucin (2019), acontece devido aos avanços que as TIC's vêm tendo e ao fácil acesso que as pessoas têm a ela; hoje, os jovens são considerados protagonistas dessa cultura tecnológica. Pode-se entender que a intenção da BNCC, ao incluir a cultura digital entre as suas competências, é a de formar alunos capazes de lidar de forma saudável com o mundo da informação digital (SEIBT, 2019).

Isso posto, o processo de ensino e aprendizagem ancorado no uso das TIC's pode ser proveitoso tanto para os alunos, como para os professores. Bittar (2011) considera que as TIC's podem auxiliar os professores na detecção da compreensão dos alunos enquanto eles aprendem os conteúdos escolares, além de poderem auxiliar no desenvolvimento do raciocínio e da autonomia dos seus estudantes.

\section{OPORTUNIDADES E LIMITAÇOES DO USO DAS TIC's}

Um dos fatores limitantes para a inserção das TIC's em sala de aula é apresentado por Reinaldo et al. (2016, p. 86), os quais destacam que: “A utilização da informática e da computabilidade pelas TIC's na educação está relativamente ociosa, devido aos receios e preconceitos dos educadores". Para os autores, muitos educadores insistem em acreditar que qualquer ferramenta que chame a atenção do aluno acabe substituindo-os.

Com a chegada das TIC's no ambiente escolar, pôde-se perceber que a escola passou a enfrentar grandes desafios. Para Barrera (2018), o uso da tecnologia encontra diversas 
limitações, tais como a dificuldade econômica de diversos alunos, e até de professores, que não possuem computador ou qualquer outro recurso tecnológico.

Para além dessas limitações, Sahb (2016) ainda inclui a falta de recursos, de infraestrutura, o despreparo dos professores e da equipe pedagógica, os materiais que chegam à escola por imposição e não por escolha dos professores, bem como a quantidade de material inadequada ao porte do colégio. Esses seriam os principais desafios a serem enfrentados.

Leite e Ribeiro (2012) consideram que, para que a inclusão das TIC's ocorra de forma positiva no ensino, é necessária a união de diversos fatores, dentre eles, é possível destacar: o domínio do professor sobre as tecnologias existentes e sua utilização na prática; a necessidade de que a escola seja dotada de uma boa estrutura física e material, que possibilite a utilização dessas tecnologias durante as aulas.

Pode-se considerar, também, que a inclusão de qualquer recurso tecnológico, por si só, não garante a melhoria da qualidade na educação. Todavia, as TIC's buscam potencializar novas possibilidades, novas estratégias de aprendizagem, para auxiliar o professor e os estudantes (ALBINO; SOUZA, 2016). Muitos autores são mais otimistas e defendem que as TIC's são uma realidade do mundo contemporâneo e que a sociedade, inclusive os sistemas educacionais, precisam se adaptar (PASSERO; ENGSTER; DAZZI, 2016).

Sob a perspectiva de Dourado et al. (2014), o mundo digital invade cada vez mais a vida cotidiana escolar e está redefinindo a escola e a maneira docente de ensinar no contexto atual. Por esse motivo, pode-se entender que, no panorama atual, é impossível viver em um mundo globalizado sem utilização das TIC's. No que se refere ao meio escolar, Dourado et al. (2014, p. 357) ainda destacam que:

\footnotetext{
Nas escolas públicas e privadas, é possível identificar o uso constante dos recursos tecnológicos pelos alunos. As ferramentas que fazem parte do uso diário são: smartphone, computador, tablet, internet, câmera digital, entre outros equipamentos que vêm dia após dia sendo essenciais na vida dos jovens.
}

Essas tecnologias facilitam o acesso a um imenso conjunto de informação e recursos, a inserção das TIC's no cotidiano escolar anima o desenvolvimento do pensamento crítico, criativo e a aprendizagem cooperativa do aluno (SANTOS, 2018). Giraffa (2013) aponta que os alunos parecem estar muito confortáveis com seus computadores, agindo como extensões de suas mãos, demonstram familiaridade com seu uso e parecem não ter problemas em resolver todas as suas questões e dúvidas com eles. 
Para Santos (2018), as TIC's são ferramentas auxiliares nas mãos dos educadores, possibilitando ao professor ser mediador, facilitador, incentivador, desafiador e investigador do conhecimento, da própria prática e da aprendizagem individual e grupal. Corroborando com Santos (2018), Júnior, Silva e Bertoldo (2020) defendem que o trabalho com as tecnologias na educação possibilita o desenvolvimento da aprendizagem criativa, tornando o aluno mais ativo na construção de seu saber.

Dessa maneira, pode-se entender que o uso de tecnologia como recurso didático no processo de ensino e aprendizagem pode alavancar substancialmente o interesse do aluno pelo que está sendo trabalhado. Sendo assim, faz-se necessário investir em cursos de formação continuada e de atualização para os professores, a fim de promover novas competências e habilidades no sentido de acompanhar os avanços tecnológicos (ASSIS; CZELUSNIAK; ROEHRIG, 2011).

\section{METODOLOGIA}

O presente artigo possui caráter de pesquisa qualitativa, de cunho exploratório, com fundamentação teórica, ancorado em documentos primários e secundários. Minayo (2009) entende a pesquisa qualitativa como sendo uma pesquisa que responde a questões muito particulares, sendo utilizada nas ciências sociais.

Para Gil (2008, p. 27): “As pesquisas exploratórias têm como principal finalidade desenvolver, esclarecer e modificar conceitos e ideias, tendo em vista a formulação de problemas mais precisos ou hipóteses pesquisáveis para estudos posteriores”. Para o autor, pesquisas desse gênero são desenvolvidas tendo como objetivo proporcionar uma visão ampla acerca de um determinado fato, tornando-o aproximável.

A coleta de dados se deu por meio de pesquisa documental e bibliográfica, esta última, sob o enfoque de Gil (2008, p. 50):

É desenvolvida a partir de material já elaborado, constituído principalmente de livros e artigos científicos. [...] a principal vantagem da pesquisa bibliográfica reside no fato de permitir ao investigador a cobertura de uma gama de fenômenos muito mais ampla do que aquela que poderia pesquisar diretamente.

No que tange à pesquisa documental, esta é definida por Marconi e Lakatos (2008) como uma pesquisa na qual a fonte dos dados está restrita a documentos, podendo estes serem documentos primários ou secundários. Para as autoras, documentos primários são aqueles 
buscados direto do autor ou do órgão que os escreveu.

Foram utilizados, então, para a construção deste artigo, os seguintes documentos primários: BNCC (2018), LDBEN (1996), PCN's (1998), DCNEB (2013), nos quais buscouse apresentar as diferentes dimensões do uso da tecnologia, em âmbito educacional, no Ensino de Ciências, destacando o que cada um apresenta e o que se altera com o passar dos anos.

A seleção das produções científicas que compõem este trabalho foi realizada a partir de buscas nas seguintes bases de dados bibliográficos: SciElo, Portal de Periódicos CAPES, Brazilian Journal of Development, além de ter sido utilizada a plataforma de buscas Google Acadêmico.

Assim sendo, foram considerados os seguintes termos combinados para a busca dos trabalhos: “uso das TIC's em âmbito educacional; “uso das TIC's no processo de ensino e aprendizagem; "uso das TIC's no Ensino de Ciências"; e "desafios e limitações do uso das TIC's".

A busca resultou em 60 trabalhos, sendo incluídos os trabalhos originais datados do ano de 2014 (pré-BNCC), seguindo até o ano de 2021 (pós-BNCC), escritos em português, os quais foram avaliados individualmente. Como critério de seleção, foi feita a leitura dos resumos desses trabalhos, do referencial teórico, dos passos metodológicos e, ainda, observou-se o quão próximo esses estudos estavam da quinta competência geral da BNCC.

Dessa forma, buscou-se, nos textos dos trabalhos, localizar evidências que fizessem jus à quinta competência geral da BNCC (2018). Excluíram-se os estudos voltados para a Educação Infantil, estudos que estavam em idioma estrangeiro, assim como estudos que não eram relevantes para o artigo em questão.

Levando em conta os critérios mencionados, 15 trabalhos foram selecionados: 13 artigos científicos, 01 dissertação de mestrado e 01 monografia de especialização, assim, abrangendo os níveis mais elevados de ensino, para que fosse demonstrado o quão eficaz pode ser a aplicabilidade da tecnologia nos diferentes segmentos do processo educacional.

Após a seleção dos estudos, realizou-se leitura guiada, seguida de categorização, e seguiram-se como critérios, para fins de tabulação, o módulo de ensino para qual o trabalho era direcionado, as temáticas abordadas por eles, as estratégias e recursos metodológicos utilizados para o desenvolvimento das atividades nos níveis mais elevados do ensino, bem como as potencialidades e limitações metodológicas que os trabalhos apresentaram.

Para fins de análise dos dados, a qual se deu qualitativamente, utilizou-se o método comparativo (GIL, 2008). Somente a BNCC (2018) foi escolhida para participar da análise 
comparativa dos dados, devido ao fato de ser o documento curricular mais recente e o que melhor trabalha a tecnologia em âmbito educacional. Além do mais, sabendo-se que a BNCC (2018) possui dez competências gerais, optou-se por trabalhar somente com a quinta, pois é justamente essa que diz respeito ao uso das TIC's, tema principal do presente artigo e dos artigos que estão compondo o quadro apresentada nos resultados deste estudo.

Portanto, valendo-se do método comparativo (GIL, 2008), foi possível fazer um confronto entre os trabalhos científicos selecionados para o quadro e o texto apresentado pela BNCC (2018) na sua quinta competência, tendo como finalidade constatar a ligação entre os trabalhos analisados e a competência geral aqui em evidência.

\section{ANÁLISE E RESULTADOS}

Para oferecer uma melhor compreensão do estudo em pauta, construiu-se o seguinte quadro (Quadro 1), sumarizando os trabalhos que tratam do uso das TIC's no ensino, não somente fundamental, mas, também, no Ensino Médio e no Ensino Superior. Esses estudos foram julgados como sendo de maior relevância para a construção desta pesquisa.

\begin{tabular}{|c|c|c|c|c|c|}
\hline $\mathbf{N}^{\circ}$ & Autor/ano/tipo & $\begin{array}{l}\text { Módulo de } \\
\text { ensino }\end{array}$ & $\begin{array}{l}\text { Temática } \\
\text { abordada }\end{array}$ & $\begin{array}{l}\text { Estratégias e } \\
\quad \text { recursos } \\
\text { metodológicos }\end{array}$ & $\begin{array}{c}\text { Potencialidades e } \\
\text { limitações } \\
\text { metodológicas } \\
\text { encontradas }\end{array}$ \\
\hline 1 & $\begin{array}{c}\text { Dourado et al. } 2014 \\
\text { Artigo }\end{array}$ & $\begin{array}{c}\text { Ensino } \\
\text { Fundamental }\end{array}$ & $\begin{array}{l}\text { Ensino dos } \\
\text { conteúdos } \\
\text { através de } \\
\text { meios visuais, } \\
\text { comunicativos } \\
\text { dinâmicos e } \\
\text { inovadores. }\end{array}$ & $\begin{array}{l}\text { Aula de campo. } \\
\text { Recursos } \\
\text { metodológicos } \\
\text { aplicação de } \\
\text { questionário } \\
\text { prévio e utilização } \\
\text { de TIC's para o } \\
\text { ensino de ciências } \\
\text { com foco na } \\
\text { utilização de de } \\
\text { laboratório de } \\
\text { informática. }\end{array}$ & $\begin{array}{l}\text { Foi constatado que não } \\
\text { haviam computadores } \\
\text { suficientes para todos os } \\
\text { alunos. } \\
\text { Todavia, para os autores, } \\
\text { os estudantes acharam a } \\
\text { intervenção pedagógica } \\
\text { fazendo uso das TIC's de } \\
\text { grande importância, } \\
\text { possibilitando } \\
\text { despertar da curiosidade } \\
\text { de algo que eles não } \\
\text { conheciam. }\end{array}$ \\
\hline 2 & $\begin{array}{c}\text { Giassi; Ramos. } \\
2016 . \\
\text { Artigo }\end{array}$ & $\begin{array}{l}\text { Ensino } \\
\text { Fundamental }\end{array}$ & $\begin{array}{l}\text { Utilização de } \\
\text { alguns tipos } \\
\text { de TIC's, com } \\
\text { o propósito de } \\
\text { incluir as } \\
\text { diversas } \\
\text { possibilidades } \\
\text { de seu uso em } \\
\text { sala de aula. }\end{array}$ & $\begin{array}{l}\text { Realizado com } \\
\text { turmas do Ensino } \\
\text { Fundamental. } \\
\text { Recursos } \\
\text { metodológicos - } \\
\text { computador, } \\
\text { programa } \\
\text { PowerPoint } \\
\text { programa Movie } \\
\text { Maker }^{\circledR} \text {, câmera e } \\
\text { gravador de áudio }^{\circledR}\end{array}$ & $\begin{array}{l}\text { As autoras perceberam } \\
\text { que os alunos sentem } \\
\text { falta de aulas mais } \\
\text { dinâmicas, e também que } \\
\text { eles gostam e se sentem } \\
\text { felizes por poderem } \\
\text { utilizar tecnologias. } \\
\text { Entretanto, para as } \\
\text { autoras, alunos e } \\
\text { professores ainda não } \\
\text { fazem parte desse }\end{array}$ \\
\hline
\end{tabular}




\begin{tabular}{|c|c|c|c|c|c|}
\hline & & & & $\begin{array}{l}\text { do celular e vídeos } \\
\text { do Youtube }{ }^{\circledast} \text {. }\end{array}$ & $\begin{array}{l}\text { processo, até porque } \\
\text { muitas escolas não } \\
\text { apresentam condições } \\
\text { materiais para isso. }\end{array}$ \\
\hline 3 & $\begin{array}{l}\text { Natalicchio. } 2019 . \\
\text { Dissertação de } \\
\text { Mestrado }\end{array}$ & $\begin{array}{c}\text { Ensino } \\
\text { Fundamental }\end{array}$ & $\begin{array}{l}\text { Utilização de } \\
\text { maquetes no } \\
\text { processo de } \\
\text { aprendizagem } \\
\text { dos alunos no } \\
\text { ensino } \\
\text { fundamental } \\
\text { mediante a } \\
\text { proposta da } \\
\text { BNCC. }\end{array}$ & $\begin{array}{l}\text { Utilização } r \\
\text { TIC's para a } \\
\text { elaboração das } \\
\text { maquetes por um } \\
\text { software 3D. } \\
\text { Recursos } \\
\text { metodológicos - } \\
\text { Sketchup, máquina } \\
\text { de corte a laser, } \\
\text { impressora 3D, } \\
\text { realidade } \\
\text { aumentada e } \\
\text { realidade virtual, } \\
\text { ferramentas PBL e } \\
\text { Framework. }\end{array}$ & 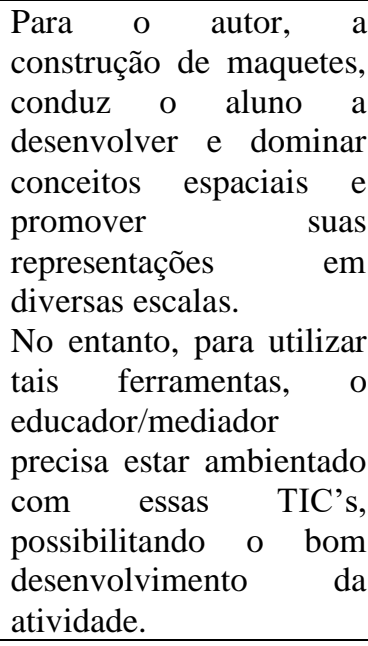 \\
\hline 4 & $\begin{array}{c}\text { Studart et al. } 2017 . \\
\text { Artigo }\end{array}$ & $\begin{array}{l}\text { Ensino } \\
\text { Fundamental }\end{array}$ & $\begin{array}{l}\text { Construção de } \\
\text { um site sobre } \\
\text { o sistema } \\
\text { reprodutor } \\
\text { humano por } \\
\text { estudantes do } \\
\text { quinto ano do } \\
\text { ensino } \\
\text { fundamental. }\end{array}$ & $\begin{array}{l}\text { Aula passeio. } \\
\text { Recursos } \\
\text { metodológicos - } \\
\text { quadro interativo, } \\
\text { projetor } \\
\text { multimídia, } \\
\text { impressora, } \\
\text { subwoofer, } \\
\text { notebook, tablets, } \\
\text { câmera } \\
\text { fotográfica, } \\
\text { webcam e quadro } \\
\text { branco. }\end{array}$ & $\begin{array}{l}\text { Os autores puderam } \\
\text { constatar que os alunos } \\
\text { assimilaram rapidamente } \\
\text { os termos científicos, e } \\
\text { que a participação dos } \\
\text { estudantes na construção } \\
\text { do site foi de forma } \\
\text { eficientemente ativa. }\end{array}$ \\
\hline 5 & $\begin{array}{c}\text { Fernandes; } \\
\text { Rodrigues; Ferreira. } \\
2015 . \\
\text { Artigo }\end{array}$ & $\begin{array}{l}\text { Ensino } \\
\text { Superior }\end{array}$ & $\begin{array}{l}\text { Proposta } \\
\text { pedagógica } \\
\text { para promover } \\
\text { o Ensino de } \\
\text { Ciências } \\
\text { através da } \\
\text { Investigação } \\
\text { (ENCI), por } \\
\text { meio de } \\
\text { Módulos } \\
\text { Temáticos } \\
\text { Virtuais } \\
\text { (MTV's). }\end{array}$ & $\begin{array}{l}\text { Utilização de sites } \\
\text { e bancos de dados } \\
\text { para elaboração de } \\
\text { modelos temáticos } \\
\text { virtuais como } \\
\text { AO's e OVA's. } \\
\text { Recursos } \\
\text { metodológicos } \\
\text { Repositórios de } \\
\text { Objetos de } \\
\text { Aprendizagem } \\
\text { (ROA), sites } \\
\text { gratuitos para } \\
\text { organização de } \\
\text { material dral } \\
\text { formato } \\
\text { multimídia. }\end{array}$ & $\begin{array}{l}\text { A utilização dos modelos } \\
\text { temáticos virtuais busca } \\
\text { favorecer a } \\
\text { argumentação dos } \\
\text { participantes por meio do } \\
\text { estímulo do professor, } \\
\text { principalmente durante o } \\
\text { levantamento de } \\
\text { hipóteses, e durante as } \\
\text { interações realizadas } \\
\text { com os recursos digitais. } \\
\text { Entretanto, uma proposta } \\
\text { como essa requer um } \\
\text { maior domínio por parte } \\
\text { do educador para poder } \\
\text { desenvolver a atividade } \\
\text { utilizando modelos } \\
\text { temáticos virtuais. }\end{array}$ \\
\hline 6 & $\begin{array}{c}\text { Shaw; Ribeiro. } \\
2014 . \\
\text { Artigo }\end{array}$ & $\begin{array}{l}\text { Ensino } \\
\text { Fundamental }\end{array}$ & $\begin{array}{l}\text { Potencialidad } \\
\text { es do uso de } \\
\text { games na } \\
\text { aprendizagem } \\
\text { de conteúdos } \\
\text { de ciências } \\
\text { por alunos do }\end{array}$ & $\begin{array}{lr}\text { Três } & \text { games } \\
\text { utilizados } & \text { para } \\
\text { estudo do sistema } & \\
\text { endócrino r } & \text { e } \\
\text { sistema nervoso. } & \\
\text { Recursos } & \\
\text { metodológicos } & -\end{array}$ & $\begin{array}{l}\text { Para os autores, os } \\
\text { games podem oferecer } \\
\text { possibilidades de } \\
\text { aumentar a motivação e } \\
\text { concentração dos alunos. } \\
\text { Contudo, alguns alunos } \\
\text { tiveram dificuldade em }\end{array}$ \\
\hline
\end{tabular}




\begin{tabular}{|c|c|c|c|c|c|}
\hline & & & $\begin{array}{l}\text { Ensino } \\
\text { Fundamental. }\end{array}$ & $\begin{array}{l}\text { game Code Fred } \\
\text { Survival Mode } \\
\text { Simon Cérebro }{ }^{\circledR}, \\
\text { Comando Imuno }{ }^{\circledR} .\end{array}$ & $\begin{array}{l}\text { ler as instruções dos } \\
\text { games, pois estava em } \\
\text { outro idioma, uma outra } \\
\text { parcela de alunos, } \\
\text { encerrou o jogo muito } \\
\text { rapidamente, ficando } \\
\text { dispersos durante o resto } \\
\text { da aula. }\end{array}$ \\
\hline 7 & $\begin{array}{c}\text { Santana et al. } 2016 . \\
\text { Artigo }\end{array}$ & $\begin{array}{l}\text { Ensino } \\
\text { Fundamental }\end{array}$ & $\begin{array}{l}\text { Uso de } \\
\text { tecnologias } \\
\text { móveis no } \\
\text { estudo dos } \\
\text { ecossistemas } \\
\text { costeiros de } \\
\text { Mata } \\
\text { Atlântica. }\end{array}$ & $\begin{array}{l}\text { Momentos } \\
\text { pedagógicos de } \\
\text { Delizoikov et al. } \\
\text { (2002). Aula de } \\
\text { campo. } \\
\text { Recursos } \\
\text { metodológicos- } \\
\text { Telefone celular, } \\
\text { aplicativo Map of } \\
\text { Life } e^{\circledR} \text { livros } \\
\text { didáticos e } \\
\text { enciclopédias. }\end{array}$ & $\begin{array}{l}\text { O uso restrito deste } \\
\text { aplicativo nos celulares } \\
\text { dos alunos se deu } \\
\text { exclusivamente em suas } \\
\text { residências, e durante a } \\
\text { aula de campo, pois a } \\
\text { escola em que a prática } \\
\text { foi desenvolvida, proíbe } \\
\text { o uso dos celulares no } \\
\text { ambiente de ensino. } \\
\text { Contudo, atribuir o uso } \\
\text { de tecnologia em aula de } \\
\text { campo constituiu um } \\
\text { fator potencializador } \\
\text { para a construção do } \\
\text { conhecimento acerca do } \\
\text { tema trabalhado. }\end{array}$ \\
\hline 8 & $\begin{array}{l}\text { Klein; Crestani; } \\
\text { Locatelli. } 2016 . \\
\text { Artigo }\end{array}$ & $\begin{array}{l}\text { Ensino } \\
\text { Superior, } \\
\text { Ensino } \\
\text { Básico }\end{array}$ & $\begin{array}{l}\text { Utilização de } \\
\text { AVA, } \\
\text { direcionado a } \\
\text { professores } \\
\text { alunos. }\end{array}$ & $\begin{array}{l}\text { Recursos } \\
\text { metodológicos - } \\
\text { Desenvolvimento } \\
\text { de Blog como } \\
\text { recurso didático } \\
\text { pedagógico no } \\
\text { ensino de ciências. }\end{array}$ & $\begin{array}{l}\text { A disponibilidade de um } \\
\text { Blog de fácil acesso, } \\
\text { tanto para os alunos, } \\
\text { quanto para os } \\
\text { professores, possibilita } \\
\text { sua utilização como uma } \\
\text { alternativa de recurso } \\
\text { didático ao professor, e } \\
\text { como material de } \\
\text { pesquisa e apoio aos } \\
\text { estudantes. }\end{array}$ \\
\hline 9 & $\begin{array}{c}\text { Santos; Gama. } \\
2021 . \\
\text { Artigo }\end{array}$ & $\begin{array}{l}\text { Ensino } \\
\text { Médio }\end{array}$ & $\begin{array}{l}\text { Uso de lives } \\
\text { interdisciplina } \\
\text { res para } \\
\text { manter os } \\
\text { estudantes } \\
\text { conectados } \\
\text { através de } \\
\text { atividades } \\
\text { remotas em } \\
\text { tempos de } \\
\text { pandemia. }\end{array}$ & $\begin{array}{l}\text { Aplicação de Lives } \\
\text { interdisciplinares. } \\
\text { Recursos } \\
\text { metodológicos - } \\
\text { plataforma } \\
\text { YouTube } \\
\text { formulários } \\
\text { Google }\end{array}$ & $\begin{array}{l}\text { Os autores puderam } \\
\text { constatar que, a } \\
\text { utilização destes recursos } \\
\text { possibilitou a criação de } \\
\text { um ambiente mais } \\
\text { motivador, em que os } \\
\text { alunos ficaram mais } \\
\text { atentos e participaram de } \\
\text { uma maneira efetiva na } \\
\text { construção do processo } \\
\text { de ensino aprendizagem. } \\
\text { Demonstrando mais uma } \\
\text { vez a eficácia das TIC's } \\
\text { no processo de ensino. }\end{array}$ \\
\hline 10 & $\begin{array}{l}\text { Pereira. } 2014 . \\
\text { Monografia de } \\
\text { especialização }\end{array}$ & $\begin{array}{c}\text { Ensino } \\
\text { Fundamental }\end{array}$ & $\begin{array}{l}\text { Possibilidade } \\
\text { de conexão } \\
\text { entre } \\
\text { professor, } \\
\text { aluno } \\
\text { tecnologia } \\
\text { com uma }\end{array}$ & $\begin{array}{l}\text { Aula expositiva } \\
\text { Recursos } \\
\text { metodológicos - } \\
\text { lousa digital, } \\
\text { computador, } \\
\text { internet. }\end{array}$ & $\begin{array}{l}\text { O interesse dos alunos no } \\
\text { decorrer das aulas se } \\
\text { mostrou crescente, } \\
\text { passando da inicial } \\
\text { curiosidade acerca da } \\
\text { nova ferramenta de } \\
\text { estudo, para real }\end{array}$ \\
\hline
\end{tabular}




\begin{tabular}{|c|c|c|c|c|c|}
\hline & & & $\begin{array}{l}\text { nova } \\
\text { metodologia. }\end{array}$ & & $\begin{array}{l}\text { empenho e dedicação } \\
\text { quanto à compreensão da } \\
\text { temática. } \\
\text { Entretanto, inicialmente, } \\
\text { o professor responsável } \\
\text { pela aula demonstrou } \\
\text { uma certa falta de tato, } \\
\text { para lidar com a lousa } \\
\text { digital, porém, após } \\
\text { buscar por informação e } \\
\text { conhecimento acerca do } \\
\text { aparelho, pôde } \\
\text { desenvolver sua prática } \\
\text { sem empecilhos. }\end{array}$ \\
\hline 11 & $\begin{array}{c}\text { Nascimento; } \\
\text { Benedetti; Santos. } \\
2020 . \\
\text { Artigo }\end{array}$ & $\begin{array}{c}\text { Ensino } \\
\text { Fundamental }\end{array}$ & $\begin{array}{l}\text { Utilização de } \\
\text { jogos digitais } \\
\text { como } \\
\text { ferramenta de } \\
\text { ensino e } \\
\text { aprendizagem } \\
\text { no ensino de } \\
\text { ciências }\end{array}$ & $\begin{array}{l}\text { Sequência didática } \\
\text { Recursos } \\
\text { metodológicos - } \\
\text { jogo digital } \\
\text { Plague Inc, } \\
\text { smartphones, } \\
\text { WhatsApp. }\end{array}$ & $\begin{array}{l}\text { Para os autores, o game } \\
\text { em pauta, se destaca } \\
\text { como uma ferramenta de } \\
\text { potencial pedagógico por } \\
\text { ser um jogo lúdico, } \\
\text { técnico e com potencial } \\
\text { educativo. } \\
\text { Além do mais, é } \\
\text { acessível a qualquer tipo } \\
\text { de smartphone, sendo } \\
\text { assim, o uso do game } \\
\text { dispensa qualquer } \\
\text { estrutura tecnológica por } \\
\text { parte da escola. }\end{array}$ \\
\hline 12 & $\begin{array}{c}\text { Jacobs et al. } 2020 . \\
\text { Artigo }\end{array}$ & $\begin{array}{l}\text { Ensino } \\
\text { Médio }\end{array}$ & $\begin{array}{l}\text { Atividades de } \\
\text { aprendizagens } \\
\text { envolvendo as } \\
\text { TIC's. }\end{array}$ & 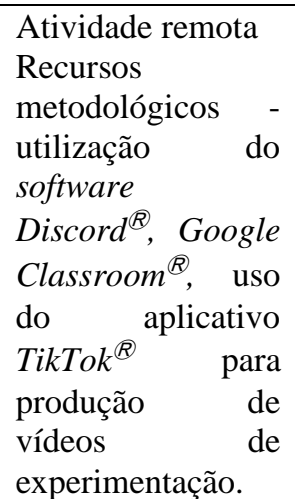 & $\begin{array}{l}\text { Atividades mais lúdicas, } \\
\text { com inclusão das TIC's, } \\
\text { obtiveram uma maior } \\
\text { adesão por parte dos } \\
\text { alunos. } \\
\text { Demonstrando que o uso } \\
\text { das tecnologias, pode } \\
\text { potencializar o interesse } \\
\text { e motivação dos alunos } \\
\text { pelo conteúdo que está } \\
\text { sendo trabalhado. }\end{array}$ \\
\hline 13 & $\begin{array}{c}\text { Carvalho et al. } \\
2020 . \\
\text { Artigo }\end{array}$ & $\begin{array}{c}\text { Ensino } \\
\text { Fundamental }\end{array}$ & $\begin{array}{l}\text { Construção de } \\
\text { um } \\
\text { biodigestor } \\
\text { para o } \\
\text { aproveitament } \\
\text { o dos resíduos } \\
\text { das } \\
\text { residências } \\
\text { dos } \\
\text { educandos. }\end{array}$ & $\begin{array}{l}\text { Sala de aula } \\
\text { invertida, ensino } \\
\text { híbrido. } \\
\text { Recursos } \\
\text { metodológicos - } \\
\text { aplicativo } \\
\text { Whatsapp, } \\
\text { software } \\
\text { PowToon }^{\circledR} \text {. }\end{array}$ & 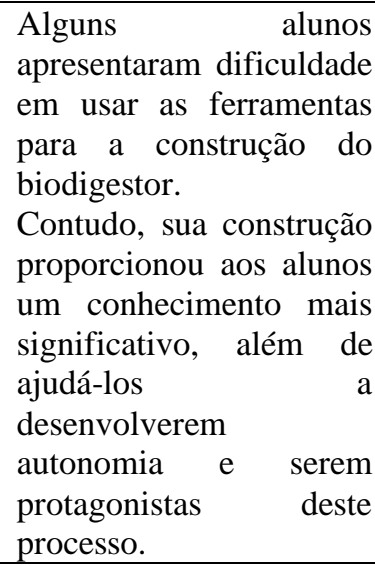 \\
\hline 14 & $\begin{array}{c}\text { Conceição; } \\
\text { Vasconcelos. } 2018 . \\
\text { Artigo }\end{array}$ & $\begin{array}{c}\text { Ensino } \\
\text { Fundamental }\end{array}$ & $\begin{array}{lr}\text { Utilização } & \text { de } \\
\text { jogos digitais } \\
\text { didáticos no } \\
\text { ensino de } \\
\text { ciências. }\end{array}$ & $\begin{array}{lr}\text { Realizado } & \text { em } \\
\text { laboratório } & \text { de } \\
\text { informática. } & \\
\text { Recursos } & \\
\text { metodológicos } & - \\
\end{array}$ & $\begin{array}{l}\text { Os autores puderam } \\
\text { comprovar a relevância } \\
\text { do jogo no processo de } \\
\text { ensino-aprendizagem, } \\
\text { demonstrando }\end{array}$ \\
\hline
\end{tabular}




\begin{tabular}{|c|c|c|c|c|c|}
\hline & & & & $\begin{array}{l}\text { software Scrath, } \\
\text { PowerPoint } \mathrm{e} \\
\text { computador. }\end{array}$ & $\begin{array}{l}\text { ferramenta como } \\
\text { elemento } \\
\text { motivador/facilitador da } \\
\text { aprendizagem dos } \\
\text { alunos. } \\
\text { Porém, neste estudo foi } \\
\text { constatado o baixo índice } \\
\text { do uso dos Laboratórios } \\
\text { de Informática pelos } \\
\text { estudantes, mesmo no } \\
\text { atual cenário tecnológico } \\
\text { e de informação. }\end{array}$ \\
\hline 15 & $\begin{array}{c}\text { Júnior; Silva; } \\
\text { Bertoldo. } 2020 . \\
\text { Artigo }\end{array}$ & $\begin{array}{l}\text { Ensino } \\
\text { Superior }\end{array}$ & $\begin{array}{l}\text { Proposta } \\
\text { pedagógica } \\
\text { fazendo uso } \\
\text { de PodCast } \\
\text { como } \\
\text { ferramenta } \\
\text { para o } \\
\text { desenvolvime } \\
\text { nto do ensino } \\
\text { e da } \\
\text { aprendizagem. }\end{array}$ & $\begin{array}{l}\text { Sequência } \\
\text { didática. } \\
\text { Recursos } \\
\text { metodológicos } \\
\text { para a proposta - } \\
\text { videoconferência, } \\
\text { postagem em } \\
\text { redes sociais e } \\
\text { aparelhos } \\
\text { celulares. }\end{array}$ & $\begin{array}{l}\text { Para os autores, o } \\
\text { PodCast permite a } \\
\text { ampliação do trabalho } \\
\text { com a oralidade, e } \\
\text { instiga a aprendizagem } \\
\text { criativa. } \\
\text { Contudo, segundo os } \\
\text { autores, o uso de } \\
\text { ferramentas tecnológicas } \\
\text { para a mediação nas } \\
\text { aulas está vinculado a } \\
\text { uma proposta pedagógica } \\
\text { que os cursos na } \\
\text { modalidade presencial } \\
\text { geralmente não possuem, } \\
\text { em que, acaba surgindo } \\
\text { tantos desafios que } \\
\text { envolvem a adoção das } \\
\text { ferramentas digitais. }\end{array}$ \\
\hline
\end{tabular}

Quadro 1 - Estudos sumarizados para fins de discussão dos resultados

Fonte: elaborada pelos autores (2021).

Voltando-se o olhar para o quadro, em um primeiro momento, é possível observar que os estudos enumerados de 1 a 15, no que tange à quinta competência geral da BNCC (2018) e sua perspectiva tecnológica, fazem jus ao exposto por esta competência. Até mesmo aqueles que são datados do período pré-BNCC, que é o caso dos trabalhos de ${ }^{\circ} 1,5$ (voltados para o ensino superior, sendo uma proposta pedagógica), 6, 7, 8 (ensino superior e ensino básico) e 10. Vale ressaltar que, para essa comparação, utilizou-se a versão final da BNCC, datada do ano de 2018.

Isso significa que, mesmo antes de o país ter um currículo nacional com uma abordagem tecnológica, o uso das TIC's já se fazia presente nas escolas. Para Fonseca et. al (2014), computadores, Tablets, celulares, iPods, redes e Internet fazem parte do cotidiano das pessoas, e as escolas estão inseridas na sociedade, o que permite incorporar, em ambiente educacional, muito do que existe nesta última.

Os trabalhos aqui enumerados de 1 a 15 possuem uma abordagem mais prática, 
propondo potencializar o ensino e utilizando os mais variados recursos tecnológicos possíveis, possibilitando aos estudantes uma maior interação com o meio escolar e tecnológico. Fonseca et al. (2014) defendem que o uso de tais recursos tecnológicos pode proporcionar ao aluno uma aprendizagem significativa por meio da interação e da comunicação. Consequentemente, permitindo uma melhoria na relação aluno-professor-tecnologia-conhecimento.

As temáticas abordadas pelos trabalhos que compõem o quadro e os recursos metodológicos utilizados pelos autores vão ao encontro do exposto pela quinta competência geral da BNCC (2018), as ferramentas e interfaces digitais utilizadas foram as mais variadas: abrangendo laboratórios de informática (trabalhos 1 e 14), softwares de computador, games educativos (trabalhos 6, 11 e 14), blogs (trabalho 8), ambientes virtuais de aprendizagem/modelos temáticos virtuais (trabalho 5), impressoras 3D (trabalho 3), aplicativos, redes sociais e smartphones.

Torna-se perceptível que, nesses estudos, as tecnologias digitais de informação e comunicação foram compreendidas, utilizadas e criadas de forma crítica e significativa (BRASIL, 2018). A BNCC ainda destaca que, "Ao aproveitar o potencial de comunicação do universo digital, a escola pode instituir novos modos de promover a aprendizagem, a interação e o compartilhamento de significados entre professores e estudantes" (BRASIL, 2018, p, 61).

Em um segundo momento, voltando mais uma vez o olhar para o quadro, entende-se que, apesar de a discussão feita até aqui e de os resultados apontarem que as TIC's podem potencializar substancialmente o processo de ensino, as limitações metodológicas surgem das mais variadas formas. Essas limitações envolvem desde a falta de equipamentos, acesso à internet, até a falta de tato do professor para com as tecnologias, quando se trata da aplicabilidade de tecnologias mais avançadas, o que exige um melhor domínio do educador.

Segundo Eicher, Buch e Buch (2018), o uso adequado e eficaz das tecnologias digitais no ensino é constante e precisa evoluir para contribuir para uma leitura de mundo digital e, nesse ensino, deve-se buscar diagnosticar os problemas, apontando caminhos para iniciativas teóricas e práticas inovadoras e positivas.

A BNCC (BRASIL, 2018) aponta que é imprescindível que a escola compreenda e incorpore as novas linguagens e seus modos de funcionamento, para que, dessa forma, eduque os estudantes para usos mais democráticos das tecnologias e para uma participação mais consciente na cultura digital.

Atrelado ao que foi citado, torna-se evidente a real e urgente necessidade de capacitação docente para o uso das tecnologias, já que, diante do atual cenário pandêmico, aos 
educadores e à escola foi imposta repentina adaptação. Sob a ótica de Rondini, Pedro e Duarte (2020), os professores precisaram transpor conteúdos e adaptar suas aulas presenciais para plataformas on-line com o emprego das Tecnologias Digitais da Informação e Comunicação (TDIC), sem preparação para isso, ou com preparação superficial, também em caráter emergencial.

Faz-se necessário que os olhares se voltem ao corpo docente; processos de formação continuada para o uso das tecnologias, as quais tanto são abordadas no corpo deste trabalho, são, sim, necessários. A tecnologia está cada vez mais presente no setor educacional; inserir recursos tecnológicos no fazer docente é um diferencial para o desenvolvimento do processo de ensino-aprendizagem. Isso, consequentemente, possibilita ao setor educacional acompanhar as iminentes mudanças tecnológicas deste mundo ultraconectado.

\section{CONSIDERAÇÕES FINAIS}

O cerne do presente estudo aporta-se na perspectiva de um mundo transformado pela covid-19, ancorado na discussão sobre a presença das TIC's nos documentos normativos da educação básica nacional, atrelado à usabilidade dessas TIC's em âmbito educacional, sobretudo, no Ensino de Ciências. A pesquisa traz para essa discussão, também, o parecer de diversos autores acerca dessas tecnologias. Assim, foi possível redigir este estudo e afirmar que se fazem necessárias a adaptação e a inovação por parte da escola e do corpo docente a essa nova forma de ensinar, que, por ora, é permanente.

Com o novo modelo de ensino adotado devido à pandemia, os alunos puderam gerenciar seu tempo e espaço; a sala de aula física, com carteiras enfileiradas e um professor à frente ministrando sua aula deu lugar a reuniões on-line em interfaces como o Google Meet ${ }^{\circledR}$, Zoom $^{\circledR}$, entre outros. Atividades e exercícios passaram a ser enviados e entregues através de plataformas como Google Classroom $^{\circledR}$, via e-mail e aplicativos como WhatsApp ${ }^{\circledR}$.

Diante desse "novo normal", que forçou a modificação dos hábitos da população, impediu as reuniões, o aperto de mãos, o abraço, e a frequência à escola e à universidade, as habilidades relacionadas à tecnologia foram exigidas de modo súbito, uma nova maneira de ver o mundo se instaurou, passou-se a vê-lo através de interfaces digitais.

Ao setor educacional impôs-se um novo modelo de ensino, o que exigiu e continua exigindo domínio, por parte dos professores, sobre as TIC's. A reformulação que o momento 
exigiu mostrou ao setor educacional, sobretudo, o quão necessário é estar atualizado com as tecnologias.

\section{REFERÊNCIAS}

ALBINO, R.; SOUZA, C. A. Avaliação do nível de uso das TIC's em escolas brasileiras: uma exploração dos dados da pesquisa "TIC Educação". Revista Economia e Gestão, Belo Horizonte, v. 16, n. 43, p. 101-125, abr./jun. 2016. Disponível em:

http://www.spell.org.br/documentos/ver/42275/avaliacao-do-nivel-de-uso-das-tics-emescolas-brasileiras--uma-exploracao-dos-dados-da-pesquisa--tic-educacao-. Acesso em: 24 set. 2021.

ARRUDA, A. C. Relação entre documentos oficiais, realidade e formação docente com as TIC: o professor que temos e o professor que desejamos. Trabalho de Conclusão de Curso (Curso de Especialização em Tecnologia, Comunicação e Técnicas de Ensino) - Universidade Tecnológica Federal do Paraná, Curitiba, 2018. Disponível em: http://repositorio.roca.utfpr.edu.br/jspui/bitstream/1/11195/1/CT_TCTE_I_2017_3.pdf. Acesso em 24 set. 2021.

ASSIS, K. K.; CZELUSNIAK, S. M.; ROEHRIG, S. A. G. A articulação entre o ensino de ciências e as TIC: desafios e possibilidades para a formação continuada. In: X Congresso Nacional de Educação - EDUCERE, I Seminário Internacional de Representações Sociais, Subjetividade e Educação, 2011, Curitiba. Anais do EDUCERE. Curitiba, 2011. Disponível em: http://educere.bruc.com.br/arquivo/pdf2011/5209_2477.pdf. Acesso em: 11 mai. 2021.

BARRERA, E. C. G. Tecnologias de informação e comunicação (TICs): uma revisão sobre seu uso no ensino médio de química no brasil. 2018. 37 f. Trabalho de Conclusão de Curso (Curso de Licenciatura em Química) - Universidade Federal do Rio Grande do Sul, Porto Alegre, 2018. Disponível em: http://hdl.handle.net/10183/181157. Acesso em: 11 mai. 2021.

BARROQUEIRO, C. H.; AMARAL, L. H.; OLIVEIRA, C. A. S. O uso das tecnologias da informação e comunicação no ensino de ciências e matemática. Revista Tecnologia e Cultura, Rio de Janeiro, n. 13, p. 45-58, jul./dez. 2011. Disponível em: https://revistas.cefetrj.br/index.php/revista-tecnologia-cultura/article/view/50/83. Acesso em: 11 mai. 2021.

BERTUSSO, F. R.; MACHADO, E. G.; TERHAAG, M. M.; MALACARNE, V. A utilização das Tecnologias de Informação e Comunicação (TICs) no ensino de Ciências: um paradigma a ser vencido. Research, Society and Development, [s.1.], v. 9, n. 12, p. 1-18. 2020. http://dx.doi.org/10.33448/rsd-v9i12.11099.

BITTAR, M. A abordagem instrumental para o estudo da integração da tecnologia na prática pedagógica do professor de matemática. Educar em Revista, Curitiba, n. esp., p. 157-171, 2011. Disponível em: The instrumental approach for the technology integration in the pedagogical practice of the mathematics teacher study (scielo.br). Acesso em: 11 mai. 2021. 
BRASIL. Ministério da Educação. Diretrizes Curriculares Nacionais da Educação Básica. Secretaria de Educação Básica. Brasília: 2013. Disponível em: index.php(mec.gov.br). Acesso em: 13 abr. 2021.

BRASIL. Lei n 9394/96. Lei de Diretrizes e Bases da Educação Nacional. Estabelece as diretrizes e bases da educação nacional. Brasília: 1996. Disponível em:

https://www.planalto.gov.br/ccivil_03/Leis/L9394.htm. Acesso em: 13 abr. 2021.

BRASIL. Ministério da Educação. Base Nacional Comum Curricular. Brasília: 2018. Disponível em:

http://basenacionalcomum.mec.gov.br/images/BNCC_EI_EF_110518_versaofinal_site.pdf.

Acesso em: 15 mar. 2021.

BRASIL. Secretaria de Educação Fundamental. Parâmetros Curriculares Nacionais: terceiro e quarto ciclos do ensino fundamental: introdução aos parâmetros curriculares nacionais. Brasília: 1998. Disponível em:

http://portal.mec.gov.br/seb/arquivos/pdf/introducao.pdf. Acesso em: 11 mai. 2021.

DOURADO, I. F.; SOUZA, K. L.; CARBO, L.; MELLO, G. J.; AZEVEDO, L. F. Uso das TIC no Ensino de Ciências na Educação Básica: uma Experiência Didática. Revista de Ensino, Educação e Ciências Humanas, Londrina, v. 15, n. esp., p. 357-365, dez. 2014. https://doi.org/10.17921/2447-8733.2014v15n0p\%25p.

EICHER, K. S.; BUCH, H. E. R.; BUCH, V. M. Ensino e Tecnologia Digital: Possibilidades e Limitações. Revista Nuances: Estudos Sobre Educação, Presidente Prudente, v. 29, n. 2, p. 156-172, maio/ago. 2018. Disponível em:

https://revista.fct.unesp.br/index.php/Nuances/article/download/5810/pdf. Acesso em: 11 mai. 2021.

FONSECA, S. A. R. S.; SHITSUKA, R.; RISEMBERG, R. I. C. S.; SHITSUKA, D. M. Biologia no Ensino Médio: os saberes e o fazer pedagógico com uso de recursos tecnológicos. Revista Biota Amazônia, Macapá, v. 4, n. 1, p. 119-125, 2014. Disponível em: http://periodicos.unifap.br/index.php/biota. Acesso em: 01 mai. 2021.

GIASSI, M. G.; RAMOS, M. C. Tecnologias da informação e comunicação no ensino e aprendizagem de ciências. Revista Dynamis, Blumenau, v. 22, n. 2, p. 52-62, 2016. Disponível em: http://proxy.furb.br/ojs/index.php/dynamis/article/download/6163/3745. Acesso em: 11 mai. 2021.

GIL, Antonio Carlos. Como elaborar projetos de pesquisa. 4. ed. São Paulo: Atlas, 2008.

GIRAFFA, L. M. M. Jornada nas Escol@ s: a nova geração de professores e alunos. Revista Tecnologias, Sociedade e Conhecimento, Campinas, v. 1, n. 12, p. 100-118, nov. 2013. Disponível em:

https://repositorio.pucrs.br/dspace/bitstream/10923/8701/2/Jornada_nas_Escol_s_A_nova_ger acao_de_professores_e_alunos.pdf. Acesso em: 11 mai. 2021.

JÚNIOR, E. A. S.; SILVA, C. F. P.; BERTOLDO, S. R. F. Educação em tempos de pandemia: 
o uso da ferramenta Podcast como estratégia de ensino. Revista de Educação, Ciência e Tecnologia do IFG, [s.1.], v. 5, n. 2, p. 31-51, jul./dez. 2020. Disponível em: http://revistas.ifg.edu.br/tecnia/article/view/815. Acesso em: 11 mai. 2021.

LEITE, W. S. S.; RIBEIRO, C. A. N. A inclusão das TICs na educação brasileira: problemas e desafios. Revista Internacional de Investigación En Educación, Javeriana, v. 5, n. 10, p. 173-187, 2012. Disponível em: https://dialnet.unirioja.es/descarga/articulo/4434902.pdf. Acesso em: 11 mai. 2021.

LIMA, E. R. P. O.; MOITA, F. M. G. S. C. A tecnologia e o ensino de química: jogos digitais como interface metodológica. In: SOUSA, R. P., MOITA, F. M. C. S. C., CARVALHO, A. B. G. (Org.). Tecnologias Digitais na Educação. Campina Grande: EDUEPB, 2011. http://dx.doi.org/10.7476/9788578791247.0006.

LUCENA, S. Culturas digitais e tecnologias móveis na educação. Educar em Revista, Curitiba, n. 59, p. 277-290, jan./mar. 2016. https://doi.org/10.1590/0104-4060.43689.

MARTINHO, T.; POMBO, L. Potencialidades das TIC no ensino das Ciências Naturais: um estudo de caso. Revista Electrónica de Enseñanza de las Ciencias, [s.1.], v. 8, n. 2, p. 527 538, 2009. Disponível em: http://reec.uvigo.es/volumenes/volumen8/ART8_Vol8_N2.pdf. Acesso em: 11 mai. 2021.

MARCONI, M. A.; LAKATOS, E. M. Técnicas de Pesquisa: planejamento e execução de pesquisas, amostragens, elaboração, análise e interpretação de dados. 7. ed. São Paulo: Atlas, 2008.

MARTINS, I. Problemas e Perspectivas Sobre a Integração CTS no Sistema Educativo Português. Revista Electrónica de Enseñanza de las Ciencias, [s.1.], v. 1, n. 1, p. 28-39. 2002. Disponível em: http://reec.uvigo.es/volumenes/volumen1/REEC_1_1_2.pdf. Acesso em: 06 fev. 2021.

MINAYO, M. C. S. Pesquisa Social: teoria, método e criatividade. 34. ed. Rio de Janeiro: Vozes, 2015.

MIRANDA, G. L. Limites e possibilidades das TIC na educação. Revista de Ciências da Educação, [s.1.], n. 3, p. 41-50, maio/ago. 2007. Disponível em:

http://sisifo.ie.ulisboa.pt/index.php/sisifo/article/view/60. Acesso em: 11 mai. 2021.

MUCIN, D. As TIC no documento BNCC: a Química nesse contexto. 2019. 37 f. Trabalho de Conclusão de Curso (Curso de Licenciatura em Química) - Universidade Tecnológica Federal do Paraná, Paraná, 2019. Disponível em:

http://repositorio.roca.utfpr.edu.br/jspui/handle/1/15706. Acesso em: 11 mai. 2021.

NASCIMENTO, E. S. A utilização da internet nas aulas de biologia: estudo de caso em uma escola da rede estadual de Alagoas. 2016. 109 f. Dissertação (Mestrado) Universidade Federal de Sergipe, Sergipe, 2016. Disponível em: https://ri.ufs.br/handle/riufs/5074. Acesso em: 11 mai. 2021.

PASSERO, G.; ENGSTER, N. E. W.; DAZZI, R. L. S. Uma revisão sobre o uso das TIC's na 
educação da geração Z. Revista Novas Tecnologias na Educação, [s.1.], v. 14, n. 2, p. 1-8, dez. 2016. https://doi.org/10.22456/1679-1916.70652.

PONTE, J. P. As TIC no início da escolaridade. In: J. P. Ponte (Org.). A formação para a integração das TIC na educação pré-escolar e no $1^{\circ}$ ciclo do ensino básico. Porto: Porto Editora, 2002. Disponível em: As TIC no início da escolaridade: Perspectivas para a ... (ul.pt). Acesso em: 11 mai. 2021.

REINALDO, F.; MAGALHÃES, D.; REIS, L. P.; GAFFURI, S.; FREDDO, A.; HALLAL, R. Impasse aos Desafios do uso de Smartphones em Sala de Aula: Investigação por Grupos Focais. Revista lbérica de Sistemas e Tecnologias de Informação, [s.1.], n. 19, p. 77-92, set. 2016. http://dx.doi.org/10.17013/risti.19.77-92.

RONDINI, C. A.; PEDRO, K. M.; DUARTE, C. S. Pandemia da COVID-19 e o Ensino Remoto Emergencial: Mudanças na Prática Docente. Revista Interfaces Científicas Educação, Aracaju, v. 10, n. 1, p. 41-57, 2020. Disponível em: https://periodicos.set.edu.br/educacao/article/view/9085. Acesso em: 11 mai. 2021.

RUBBA, P.; WIESENMAYER, R. Goals and competencies for precollege STS education: recommendations based upon recent literature in environmental education. Journal of Environmental Education, [s.1.], v. 4, n.19, p. 38-44, 1988.:

https://doi.org/10.1080/00958964.1988.9942772.

SAHB, Warlley Ferreira. Tecnologias digitais da informação e comunicação e o processo de expansão e integração da educação superior no MERCOSUL. 2016. 185 f. Tese (Doutorado) - Pontifícia Universidade Católica de São Paulo, São Paulo, 2016. Disponível em; https://tede2.pucsp.br/bitstream/handle/9879/1/Warlley\%20Ferreira\%20Sahb.pdf. Acesso em: 11 maio 2021.

SANTOS, D. S. Tecnologias de Informação e Comunicação (TICs): uma abordagem no ensino remoto de Química e nanotecnologia nas escolas em tempos de distanciamento social. Revista Latino-Americana de Estudos Científicos, [s.1.], v. 2, n. 7, p. 15-25. 2021. http://dx.doi.org/10.46375/relaec.33855.

SANTOS, J. W. S. O uso das TIC's no Ensino de Ciências. 2018. 71 f. Trabalho de Conclusão de Curso (Curso de Licenciatura em Ciências Biológicas) - Universidade Federal de Campina Grande, Campina Grande, 2018. Disponível em:

http://dspace.sti.ufcg.edu.br:8080/jspui/handle/riufcg/6652. Acesso em: 15 mai. 2021.

SANTANA, R. C. M.; VIEIRA, L. S. L.; RIBEIRO, G. A. M.; SONDERMANN; D. V. C.; NOBRE, I. A. M. O uso de tecnologias móveis no ensino de ciências: uma experiência sobre o estudo dos ecossistemas costeiros da mata atlântica sul capixaba. Revista Ibero-Americana de Estudos em Educação, [s.1.], v. 11, n. 4, p. 2234-2244, 2016.

http://dx.doi.org/10.21723/riaee.v11.n4.9122.

SEIBT, I. P. S. BNCC- Base Nacional Comum Curricular: a abordagem da Tecnologia da Informação e Comunicação (TIC's) nas séries finais do ensino fundamental. 2019. 44 f. Trabalho de Conclusão de Curso (Curso de Especialização em Mídias na Educação) Universidade Federal do Rio Grande do Sul, Porto Alegre, 2019. Disponível em: 
https://www.lume.ufrgs.br/handle/10183/200569. Acesso em: 11 mai. 2021.

SOARES, L. V.; COLARES, M. L. I. S. Educação e tecnologias em tempos de pandemia no Brasil. Revista Debates em Educação, Maceió, v. 12, n. 28, p. 19-41, set./dez. 2020. http://dx.doi.org/10.28998/21756600.2020v12n28p19-41.

SOFFNER, R. Tecnologia e educação: um diálogo Freire - Papert. Revista Tópicos Educacionais, Recife, v. 19, n. 1, p. 147-162, jan./jun. 2013. Disponível em: 18549 (ufpe.br). Acesso em: 11 mai. 2021.

\section{APÊNDICE 1}

\section{AGRADECIMENTOS}

Este trabalho só foi possível devido ao engajamento e força de vontade para com a pesquisa na área da educação em Ciências e Biologia dos autores aqui envolvidos. Portanto, os agradecimentos pelo apoio, contribuição e engajamento aqui se fazem presentes.

\section{FINANCIAMENTO}

Financiado pelos próprios autores

\section{CONTRIBUIÇÕES DE AUTORIA}

Resumo/Abstract/Resumen: Luan Mesquita Guerra e André Ricardo Ghidini Introdução: Luan Mesquita Guerra Referencial teórico: Luan Mesquita Guerra e José Victor Acioli da Rosa Análise de dados: Luan Mesquita Guerra e André Ricardo Ghidini Discussão dos resultados: Luan Mesquita Guerra e André Ricardo Ghidini Conclusão e considerações finais: Luan Mesquita Guerra Referências: Luan Mesquita Guerra Revisão do manuscrito: André Ricardo Ghidini e José Victor Acioli da Rosa. Aprovação da versão final publicada: Luan Mesquita Guerra

\section{CONFLITOS DE INTERESSE}

Os autores declararam não haver nenhum conflito de interesse de ordem pessoal, comercial, acadêmico, político e financeiro referente a este manuscrito.

\section{DISPONIBILIDADE DE DADOS DE PESQUISA}

O conjunto de dados que dá suporte aos resultados da pesquisa foi publicado no próprio artigo.

\section{CONSENTIMENTO DE USO DE IMAGEM}

Não se aplica.

\section{APROVAÇÃO DE COMITÊ DE ÉTICA EM PESQUISA \\ Não se aplica.}

\section{COMO CITAR - ABNT}

GUERRA, Luan Mesquita; GHIDINI, André Ricardo; ROSA, José Victor Acioli da. A BNCC e o Ensino de Ciências: oportunidades e limitações. REAMEC - Rede Amazônica de Educação em Ciências e Matemática. Cuiabá, v. 9, n. 3, e21078, set./dez., 2021. https://doi.org/10.26571/reamec.v9i3.12385

COMO CITAR - APA

Guerra, L. M., Ghidini, A. R., \& Rosa, J. V. A. (2021). A BNCC e o Ensino de Ciências: Oportunidades e limitações. REAMEC - Rede Amazônica de Educação em Ciências e Matemática, 9(3), e21078. https://doi.org/10.26571/reamec.v9i3.12385 


\section{LICENÇA DE USO}

Licenciado sob a Licença Creative Commons Attribution-NonCommercial 4.0 International (CC BY-NC 4.0). Esta licença permite compartilhar, copiar, redistribuir o manuscrito em qualquer meio ou formato. Além disso, permite adaptar, remixar, transformar e construir sobre o material, desde que seja atribuído o devido crédito de autoria e publicação inicial neste periódico.

\section{DIREITOS AUTORAIS}

Os direitos autorais são mantidos pelos autores, os quais concedem à Revista REAMEC - Rede Amazônica de Educação em Ciências e Matemática - os direitos exclusivos de primeira publicação. Os autores não serão remunerados pela publicação de trabalhos neste periódico. Os autores têm autorização para assumir contratos adicionais separadamente, para distribuição não exclusiva da versão do trabalho publicada neste periódico (ex.: publicar em repositório institucional, em site pessoal, publicar uma tradução, ou como capítulo de livro), com reconhecimento de autoria e publicação inicial neste periódico. Os editores da Revista têm o direito de proceder a ajustes textuais e de adequação às normas da publicação.

\section{PUBLISHER}

Universidade Federal de Mato Grosso. Programa de Pós-graduação em Educação em Ciências e Matemática (PPGECEM) da Rede Amazônica de Educação em Ciências e Matemática (REAMEC). Publicação no Portal de Periódicos UFMT. As ideias expressadas neste artigo são de responsabilidade de seus autores, não representando, necessariamente, a opinião dos editores ou da referida universidade.

\section{EDITOR}

Patrícia Rosinke (D) 0

\section{HISTÓRICO}

Submetido: 14 de maio de 2021.

Aprovado: 12 de setembro de 2021.

Publicado: 28 de setembro de 2021. 